\title{
Management outcomes of primary pulmonary vein stenosis
}

\author{
Joshua M. Rosenblum, MD, PhD, ${ }^{a}$ Husnu Firat Altin, MD, ${ }^{a}$ Scott E. Gillespie, MS, ${ }^{b}$ \\ Holly Bauser-Heaton, MD, PhD, ${ }^{\mathrm{c}}$ Kirk A. Kanter, MD, ${ }^{\mathrm{a}}$ Raina Sinha, MD, MPH, ${ }^{\mathrm{a}}$ Melinda Cory, MD,${ }^{\mathrm{c}}$ and \\ Bahaaldin Alsoufi, MD ${ }^{\mathrm{d}}$
}

\section{ABSTRACT}

Objectives: Primary pulmonary vein stenosis (PPVS) is increasingly diagnosed in children with no prior pulmonary vein intervention history, and management is challenging. We describe characteristics of patients who underwent surgical repair of PPVS at our center, and examine factors associated with treatment failures.

Methods: A retrospective review of all patients who underwent surgical intervention for PPVS (2002-2016) was completed. Patients who had undergone prior cardiac surgery involving the pulmonary veins or atrial switch were excluded. Regression analyses were performed to examine characteristics, PPVS features, including severity score, and surgical details associated with treatment failures.

Results: Thirty-four children underwent initial surgical intervention for PPVS. Median age was 8.9 months (interquartile range, 5.9-18.4 months). Most patients $(\mathrm{n}=31 ; 91 \%)$ had unilateral pulmonary vein involvement and the median PPVS severity score was 3.5 (interquartile range, 3-5). On competing risk analysis, 1 year following surgical repair, $9 \%$ of patients had died, $14 \%$ had undergone reintervention, and $77 \%$ were alive without reintervention; at 5 years the numbers were $9 \%, 30 \%$, and $61 \%$, respectively. Factors associated with mortality included bilateral disease and PPVS severity score $>6$. Bilateral disease and PPVS severity score $>5$ were associated with reintervention risk.

Conclusions: Multidisciplinary management strategy is required for PPVS. Despite satisfactory early repair, patients continue to be at risk for recurrence and subsequent mortality, especially those with extensive primary involvement. The disappointing results underscore the need for multi-institutional collaborations to better understand this complex disease, establish management and follow-up protocols, and explore investigational treatment modalities that could modify the unfavorable outcome of this uncommon and challenging disease. (J Thorac Cardiovasc Surg 2020;159:1029-36)

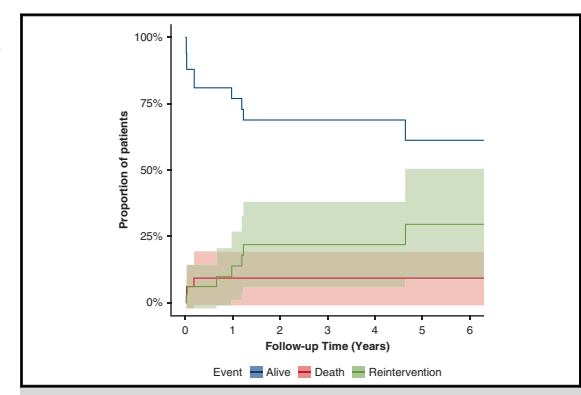

Competing risk analysis of events (eg, death and reinterventions) after surgical repair of PPVS.

\section{Central Message}

Primary pulmonary vein stenosis management is multimodal and continues to be associated with recurrence and mortality risks.

\section{Perspective}

PPVS is associated with prematurity and other congenital heart defects. In this study, we demonstrate that despite satisfactory early relief of obstruction, recurrence is not uncommon and a number of patients require surgical repair with variable success, underlining the importance of a multidisciplinary approach and investigational measures to treat this difficult pathology.

See Commentaries on pages 1037 and 1039.

\footnotetext{
From the ${ }^{\mathrm{a} D i v i s i o n}$ of Cardiothoracic Surgery, ${ }^{\mathrm{b}}$ Department of Biostatistics, and ${ }^{\mathrm{c}} \mathrm{Sib}-$ ley Heart Center, Children's Healthcare of Atlanta, Emory University School of Medicine, Atlanta, Ga; and ${ }^{\mathrm{d}}$ Department of Cardiothoracic Surgery, University of Louisville School of Medicine, Norton Children's Hospital, Louisville, Ky.

Read at the 43rd Annual Meeting of the Western Thoracic Surgical Association, Colorado Springs, Colorado, June 21-24, 2017.

Received for publication July 4, 2017; revisions received Aug 23, 2019; accepted for publication Aug 24, 2019; available ahead of print Oct 21, 2019.

Address for reprints: Bahaaldin Alsoufi, MD, Department of Cardiothoracic Surgery, University of Louisville School of Medicine, Norton Children's Hospital, 201 Abraham Flexner Way, Louisville, KY 40202 (E-mail: balsoufi@hotmail.com). $0022-5223 / \$ 36.00$

Copyright (C) 2019 by The American Association for Thoracic Surgery https://doi.org/10.1016/j.jtcvs.2019.08.105
}

Primary pulmonary vein stenosis (PPVS) is a rare congenital cardiac disease that is often recognized during early infancy. ${ }^{1-6}$ PPVS is a heterogeneous disorder and variations exist in the number of involved pulmonary veins, location of those veins, and level of stenosis (eg, discrete ostial,

Scanning this QR code will take
you to the article title page to
access supplementary informa-
tion.




\section{Abbreviations and Acronyms \\ PPVS = primary pulmonary vein stenosis \\ $\mathrm{TAPVC}=$ total anomalous pulmonary venous connection}

multifocal, or diffuse). The clinical presentation subsequently varies based on the extent of disease, related pulmonary hypertension and right heart failure, prematurity, and associated cardiac and extracardiac anomalies. ${ }^{1-6}$

Management of infants with PPVS is challenging. The majority of reports in the literature have focused on surgical management of pulmonary vein stenosis subsequent to total anomalous pulmonary venous connection (TAPVC) repair. ${ }^{7-15}$ Nonetheless, the histopathology of PPVS might differ from that of stenosis following TAPVC repair, which is commonly related to scar formation at the anastomosis site. On the other hand, the histopathology of PPVS usually involves neointimal hyperplasia and medial hypertrophy that can be localized or more commonly diffuse. ${ }^{16-18}$ Only a few reports in the literature were dedicated to describe outcomes of surgical or percutaneous repair of PPVS and they demonstrated unfavorable outcomes characterized by high operative death, recurrence of stenosis, and late mortality. ${ }^{1-6}$

Several surgical, percutaneous, and medical advances have been described in the management of pulmonary vein stenosis. Although the introduction of the sutureless surgical techniques for the treatment of pulmonary vein stenosis along with marsipulization or excision of the stenotic segments has been associated with improved early and late results, the bulk of the existing experience is in patients who had prior TAPVC repair, and early failures and late recurrences continue to plague the outlook of some of those patients. $^{7,11,13-15,19-22}$ Given the ongoing challenges, different treatment modalities, including percutaneous intervention utilizing balloon angioplasty, cutting balloons, and stenting in addition to adjunctive chemotherapeutic medications have been applied in those patients in an effort to improve intervention durability and patient survival. ${ }^{23-29}$

We aim in the current series to describe characteristics of children who underwent surgical intervention for PPVS at our institution, to report early and late outcomes, and to examine factors associated with treatment failures defined as recurrent stenosis, reintervention, or death.

\section{PATIENTS AND METHODS \\ Inclusion Criteria}

A retrospective chart review of all children who underwent surgical intervention for PPVS at Children's Healthcare of Atlanta at Emory University from 2002 to 2016 was conducted. Patients were excluded from the study if they had prior pulmonary vein intervention, prior repair of TAPVC or partial anomalous pulmonary venous connection, or prior atrial switch operation. Demographic, anatomic, imaging, operative, and hospital details were abstracted from medical records for analysis. Approval of this study was obtained from our hospital's institutional review board and requirement for individual consent was waived for this observational study.

\section{Patient Evaluation}

Our institution's multidisciplinary team that consisted of cardiac surgeons, intensivists, radiologists, and interventional cardiologists evaluated all those patients. The initial diagnosis was made by echocardiography that determined the site and degree of stenosis in addition to associated cardiac anomalies. Those patients subsequently underwent diagnostic cardiac catheterization to confirm the diagnosis, to define the level of stenosis and the status of downstream pulmonary veins, and to provide hemodynamic assessment of the pulmonary vasculature. Most recently, computed tomography angiography was utilized as a substitute to cardiac catheterization to define the level of stenosis and the status of downstream pulmonary veins. All patients were discussed at our institutions' multidisciplinary conference and consequently referred for surgical or percutaneous intervention. Surgical repair was selected in the majority of patients, whereas percutaneous intervention was generally used in those with severe comorbidities, diffuse disease with hypoplastic intraparenchymal pulmonary veins, or in those with mild isolated pulmonary vein stenosis. Subsequent to surgical repair, many patients underwent predischarge diagnostic cardiac catheterization to determine the degree of residual stenosis and need for subsequent follow-up or intervention.

\section{PPVS Severity Score}

We utilized the PPVS severity score that has been previously adopted by Kalfa and colleagues ${ }^{3}$ when they reported their European/North American multi-institutional series of patients with PPVS. In summary, each vein was assessed by echocardiography preoperatively, and that assessment was supplemented by angiography in $77 \%$ of cases. In our more recent experience, computed tomography angiographic evaluation of the pulmonary veins has become routinely used in the workup of patients with PPVS and those findings can be used to determine the severity score.

The score is based on the degree of the stenosis evaluated by measurement of the pressure gradient at the junction between the pulmonary veins and the left atrium, on the extent of the stenosis evaluated by the combined imaging modalities mentioned above (graded to focal vs diffuse disease), and finally on the number of pulmonary veins affected and the presence of unilateral versus bilateral disease. The degree of stenosis was graded as none, mild, moderate, or severe based on mean echocardiography gradients of $<2 \mathrm{~mm} \mathrm{Hg}, 2$ to $4 \mathrm{~mm} \mathrm{Hg}, 5$ to $7 \mathrm{~mm} \mathrm{Hg}$, and $>7 \mathrm{~mm} \mathrm{Hg}$, respectively. The stenosis was described as focal when affecting a very short length of the pulmonary vein and associated with upstream dilatation of the pulmonary vein, and as diffuse when affecting a significant length of the pulmonary vein with no upstream dilation of the pulmonary vein.

Each vein was given a score of 0 (no stenosis), 1.0 (mild focal), 1.5 (mild diffuse), 2.0 (moderate focal), 2.5 (moderate diffuse), 3.0 (severe focal), 3.5 (severe diffuse), or 4.0 (atresia). The severity score is the result of the sum of all 4 individual pulmonary vein scores, with an additional 2.0 added if the disease is bilateral (score range, 0-18). The severity score was confirmed by a single cardiologist (Figure E1).

\section{Statistical Analysis}

Descriptive statistics are presented as mean \pm standard deviation or median with interquartile range (IQR) for continuous variables, and with counts and percentages for categorical variables, as appropriate. Demographic, clinical, and hospital characteristics were summarized. Comparisons between various subgroups were made using $t$ tests or Mann-Whitney $U$ tests for continuous variables and $\chi^{2}$ tests of independence or Fisher exact tests in discrete cases. 
Patient mortality was assessed using Kaplan-Meier curves. Covariate associations with time until death were univariably considered via Cox proportional hazards regression models. In situations where discrete, univariable regression associations were found, stratified Kaplan-Meier curves were plotted to demonstrate differences in curve trajectories over follow-up time, and accompanied by long-rank $P$ values. The assumption of proportional hazards was checked in all cases, and model fits were gauged using log-likelihood and Akaike information criterion statistics. Results from all models are reported as hazard ratio (HR) and 95\% confidence interval (CI). Due to limitations in sample size, multivariable regression was not employed. Maximally selected rank statistics were used to find the best cut point of PPVS severity score for each of the mortality and reintervention outcomes. Rank statistics were calculated for each PPVS severity score. The maximum statistic was then taken for each of mortality and reintervention, after adjusting for follow-up time. These maximum statistics provided the best separation of outcome data into 2 groups. Cut points were then determined (PPVS severity score of 6 for mortality and 5 for reintervention) and HRs were modeled.

Freedom from reintervention and patient mortality was modeled using semiparametric, survival methods introduced by Fine and Gray. ${ }^{30}$ Specifically, a competing risks analysis was performed to obtain the probability over time to occurrence of 2 mutually exclusive end points: pulmonary vein reintervention and patient mortality following the initial surgical or percutaneous procedure. The remaining patients were alive without reintervention. The probability of each end point over 6 years of follow-up is provided via stepwise functional curves with $95 \%$ CIs. Freedom from reintervention was further evaluated using Kaplan-Meier curves and Cox regression models, as previously described for patient mortality. All statistical analyses were performed using SAS version 9.4 (SAS Institute Inc, Cary, NC) and CRAN R version 3.3 (R Foundation for Statistical Computing, Vienna, Austria).

\section{Follow-up}

Time-related outcomes were determined from outpatient office visits and inpatient records documented in the Children's Healthcare of Atlanta electronic medical record. Direct correspondence with cardiologists outside the system was also used to determine follow-up. Median followup duration was 4.3 years (IQR, 1.7-8.0 years). Follow-up was $100 \%$ complete.

\section{RESULTS}

\section{Patient Characteristics and Operative Details}

Thirty-four infants underwent surgical repair of PPVS. The cohort included 14 boys $(41.2 \%)$ with median age at intervention of 8.9 months (IQR, 5.9-18.4 months). Six patients $(17.7 \%)$ were born prematurely $(\leq 36$ weeks gestation), and $9(26.5 \%)$ had a genetic syndrome. In most patients, PPVS involved 1 to 2 pulmonary veins $(\mathrm{n}=31$; $91.2 \%)$ and was unilateral $(\mathrm{n}=31 ; 91.2 \%)$. Median pulmonary vein gradient before intervention was $10 \mathrm{~mm} \mathrm{Hg}$ (IQR, 8-13 $\mathrm{mm} \mathrm{Hg}$ ) and 4 veins had atresia. The median PPVS severity score was 3.5 (IQR, 3-5).

Among all patients, $3(8.8 \%)$ had isolated pulmonary vein stenosis, whereas the remaining $31(91.2 \%)$ had associated congenital heart anomalies, including single ventricle $(\mathrm{n}=9)$, atrial septal or ventricular septal defect $(\mathrm{n}=9)$, atrioventricular septal defect $(\mathrm{n}=5)$, coarctation of the aorta or hypoplasia of the aortic arch $(n=4)$, tetralogy of Fallot $(n=2)$, double outlet right ventricle $(n=1)$, and congenital mitral stenosis $(\mathrm{n}=1)$. Twenty patients
$(58.9 \%)$ had undergone prior surgical repair or palliation of associated congenital heart disease. Concomitant cardiac procedures were performed in 30 patients $(88.2 \%)$. The repair of PPVS was accomplished with the use of the sutureless technique $(\mathrm{n}=28 ; 82.4 \%)$, patch augmentation $(\mathrm{n}=3$, $8.8 \%$ ), or hybrid intraoperative dilatation of the stenotic vein $(\mathrm{n}=3 ; 8.8 \%)$.

During the same study period, 12 additional infants with PPVS underwent initial percutaneous intervention at our institution. Although we aim to neither include those patients in our study cohort nor compare outcomes between the 2 treatment modalities given our institutional bias, we provide the characteristics of patients who underwent surgical versus percutaneous intervention in details in Table E1 to provide the full scope of this disease. With the exception of a significantly higher rate of prematurity in the percutaneous intervention cohort $83.3 \%$ versus $17.7 \%$ $(P<.001)$, there were no significant differences between the groups.

\section{Early Hospital Outcomes}

Median maximum pulmonary vein gradients before intervention were $10 \mathrm{~mm} \mathrm{Hg}$ (IQR, 8-13 mm Hg). These gradients were reduced to $0 \mathrm{~mm} \mathrm{Hg}$ (IQR, $0-2 \mathrm{~mm} \mathrm{Hg}$ ) following surgical repair. However, 4 patients $(11.8 \%)$ had residual stenosis noted on predischarge imaging, and $2(5.9 \%)$ underwent early reinterventions: 1 surgical and 1 percutaneous.

Early hospital death occurred in 3 patients $(8.8 \%)$ : 1 patient failed extracorporeal membrane oxygenation wean, 1 patient had poor ventricular function and low cardiac output, and 1 patient had severe residual stenosis and pulmonary hypertension.

\section{Late Outcomes and Factors Affecting Outcomes}

On follow-up after surgical repair of PPVS, 4 patients died without additional pulmonary vein intervention (including 3 hospital mortalities), 7 underwent reintervention for recurrent obstruction (4 percutaneous and 3 surgical), and 23 were alive and free from reintervention. Among the 7 patients who underwent pulmonary vein reintervention, 5 were alive at final follow up. Competing risk analysis of events (eg, reintervention and death) is shown in Figure 1. At 1 year following PPVS surgery, 9\% had died, $14 \%$ had undergone reintervention, and $77 \%$ were alive without reintervention; at 5 years the numbers were $9 \%, 30 \%$, and $61 \%$, respectively. Overall survival at 1 and 5 years was $88 \%$ and $85 \%$, respectively (Figure 2).

Univariate regression analysis was performed to determine factors associated with mortality and for reintervention (Table 1). Bilateral pulmonary vein involvement (HR, 6.26; 95\% CI, 1.14-34.36; $P=.035)$ and PPVS severity score $>6$ (HR, 7.21; 95\% CI, 1.01-51.3; $P=.049$ ) were associated with mortality (Figure 3 ). 


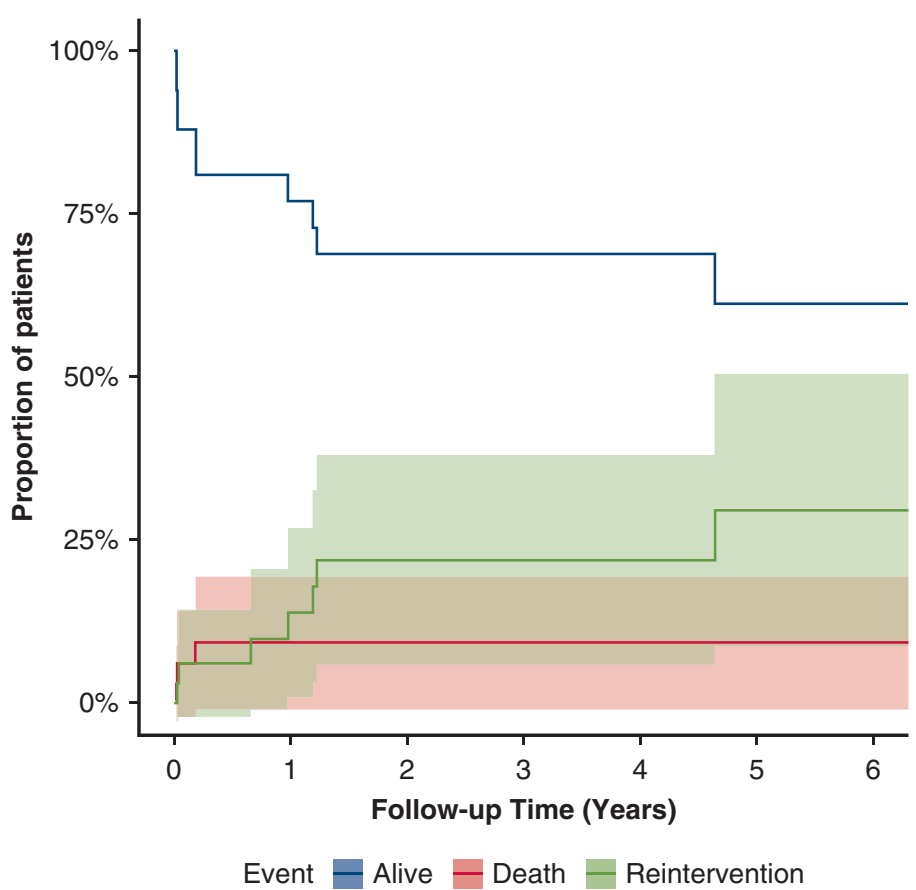

FIGURE 1. Competing risk analysis of events (ie, reinterventions [green] and death [red]) following surgical repair of primary pulmonary vein stenosis. Stepwise functional curves and $95 \%$ confidence intervals are modeled, with alive without reintervention (blue) being inferred from the outcome curves. At 1 year following surgery, $9 \%$ had died, $14 \%$ had undergone reintervention, and $77 \%$ were alive without reintervention; at 5 years the numbers were $9 \%$, $30 \%$, and $61 \%$, respectively.

Overall freedom from pulmonary venous reintervention was $85 \%$ at 1 year and $68 \%$ at 5 years. Similar to mortality, bilateral pulmonary vein involvement (HR, 5.65; 95\% CI, 1.07-29.77; $P=.041$ ) and PPVS severity score $>5$ (HR, $4.52 ; 95 \% \mathrm{CI}, 0.90-22.6 ; P=.066)$ were associated or marginally associated with reintervention risk.

\section{DISCUSSION}

PPVS is a rare congenital cardiac disease that is increasingly recognized as a management challenge. ${ }^{1-6}$ The diagnosis of PPVS might have steadily increased during the current era owing to advances in imaging modalities in addition to the higher incidence of prematurity and genetic syndromes in infants undergoing surgical palliation or repair of their congenital heart defects. ${ }^{1-6,31,32}$ The association of PPVS with other congenital heart anomalies is well known in the literature and in the current series; that incidence was $83 \%$, comparable to other published reports. ${ }^{1-6,31}$

Although the association of some of the abovementioned factors and PPVS is well established, the pathophysiology of this disease remains unclear. Several groups have investigated the biophysical origins of PPVS. At the histologic level, neointimal and myofibroblast proliferation appears to play a role in development of PPVS. ${ }^{16}$ Recently, the $E I-F 2 A K 4$ (also known as GCN2) gene was identified to be associated with pulmonary veno-occlusive disease due to uncontrolled endothelial and smooth muscle proliferation response. ${ }^{33,34}$ Animal models of PPVS have provided some insights into the dynamics associated with stenosis, and have demonstrated breakdown of the internal elastic lamina and migration of smooth muscle cells from the media to subendothelium, contributing to progressive luminal narrowing. ${ }^{16}$ Although surgery and angioplasty can manage physical stenosis, progressive and recurrent disease may be related to a biochemical alteration in the vascular composition, especially in the upstream intraparenchymal locations. ${ }^{17}$ As a result, it is plausible that the natural and modified history of PPVS might differ from that for the better-studied pulmonary vein stenosis following TAPVC repair.

Our study demonstrated that despite advances in surgical techniques, percutaneous interventions and perioperative care, PPVS continues to be associated with unfavorable outcomes, including early mortality, recurrence of stenosis requiring reinterventions, and late attrition. Those findings parallel those from other published reports that have shown survival ranging between $50 \%$ and $90 \%$ at 5 years and reintervention rate ranging between $40 \%$ and $50 \%$ at 5 years. ${ }^{1-6}$ The wide range in survival is likely reflective of patient selection in those different series. The incidence of bilateral disease in our series seems to be lower than that of other reported series, explaining the better survival in our study compared with others. 


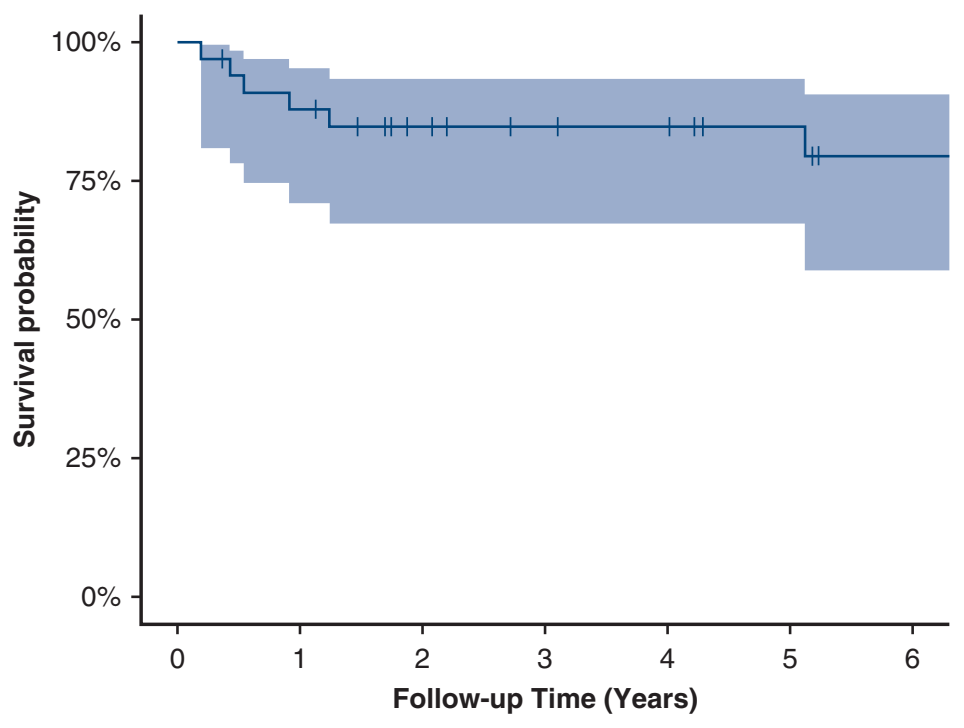

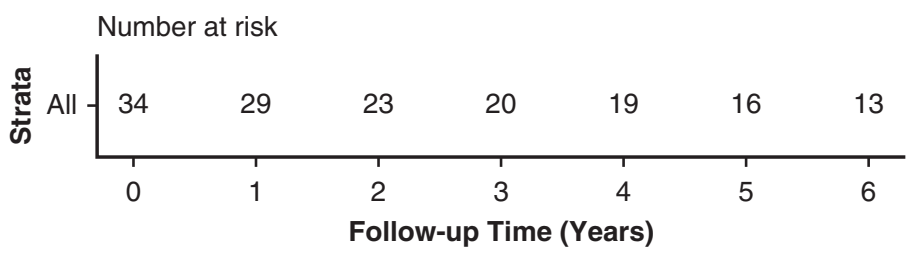

FIGURE 2. Kaplan-Meier survival (including $95 \%$ confidence intervals) following surgical repair of primary pulmonary vein stenosis. Overall survival at 1 and 5 years is $88 \%$ and $85 \%$, respectively.

We examined factors associated with poor outcomes in our current series. Although prematurity is present commonly in patients with PPVS, many of those premature patients with PPVS underwent initial percutaneous intervention at our institution and therefore the incidence of prematurity is underrepresented in the current series of surgical

TABLE 1. Cox proportional hazards univariable regression model for overall mortality and pulmonary vein reintervention in 34 children who underwent surgical repair of primary pulmonary vein stenosis (PPVS) $(n=34 ; 6$ deaths and 7 reinterventions)

\begin{tabular}{|c|c|c|c|c|}
\hline \multirow[b]{2}{*}{ Variable } & \multicolumn{2}{|l|}{ Mortality } & \multicolumn{2}{|c|}{ Reintervention } \\
\hline & $\begin{array}{c}\text { Hazard ratio } \\
(95 \% \text { confidence interval })\end{array}$ & $P$ value & $\begin{array}{c}\text { Hazard ratio } \\
(95 \% \text { confidence interval })\end{array}$ & $P$ value \\
\hline Male gender & $0.71(0.13-3.89)$ & .695 & $0.44(0.08-2.31)$ & .330 \\
\hline Age, 1-mo increase & $0.79(0.58-1.07)$ & .127 & $0.97(0.91-1.03)$ & .342 \\
\hline Prematurity* & $2.34(0.43-12.8)$ & .327 & $1.62(0.31-8.36)$ & .566 \\
\hline Genetic syndrome & $0.53(0.06-4.57)$ & .566 & $0.46(0.06-3.84)$ & .474 \\
\hline Maximum preoperative gradient $>12 \mathrm{~mm} \mathrm{Hg}$ & $0.70(0.07-6.78)$ & .762 & $2.62(0.44-15.71)$ & .292 \\
\hline Single ventricle & $0.32(0.04-2.78)$ & .303 & $4.28(0.83-22.15)$ & .083 \\
\hline Weight, 2-kg increase & $0.64(0.32-1.29)$ & .213 & $0.98(0.71-1.34)$ & .883 \\
\hline Prior cardiac surgery & $0.73(0.15-3.63)$ & .702 & $2.30(0.44-11.88)$ & .322 \\
\hline Bilateral disease & $6.26(1.14-34.4)$ & .035 & $5.65(1.07-29.77)$ & .041 \\
\hline $\begin{array}{l}\text { No. of affected veins } \\
3 \text { or } 4 \\
1 \text { or } 2\end{array}$ & $\begin{array}{c}2.87(1.33-6.19) \\
6.26(1.14-34.4) \\
\quad \text { Reference }\end{array}$ & $\begin{array}{l}.007 \\
.035\end{array}$ & $\begin{array}{l}3.25(1.25-8.40) \\
5.65(1.07-29.77)\end{array}$ & $\begin{array}{l}.015 \\
.041\end{array}$ \\
\hline \multicolumn{5}{|l|}{ PPVS severity score, 1 unit increase } \\
\hline$>6$ & $1.47(1.12-1.94)$ & .006 & $1.61(1.16-2.24)$ & .004 \\
\hline$>5$ & $7.21(1.01-51.3)$ & .049 & $4.52(0.90-22.6)$ & .066 \\
\hline
\end{tabular}

PPVS, Primary pulmonary vein stenosis. "Defined as $\leq 36$ weeks. 


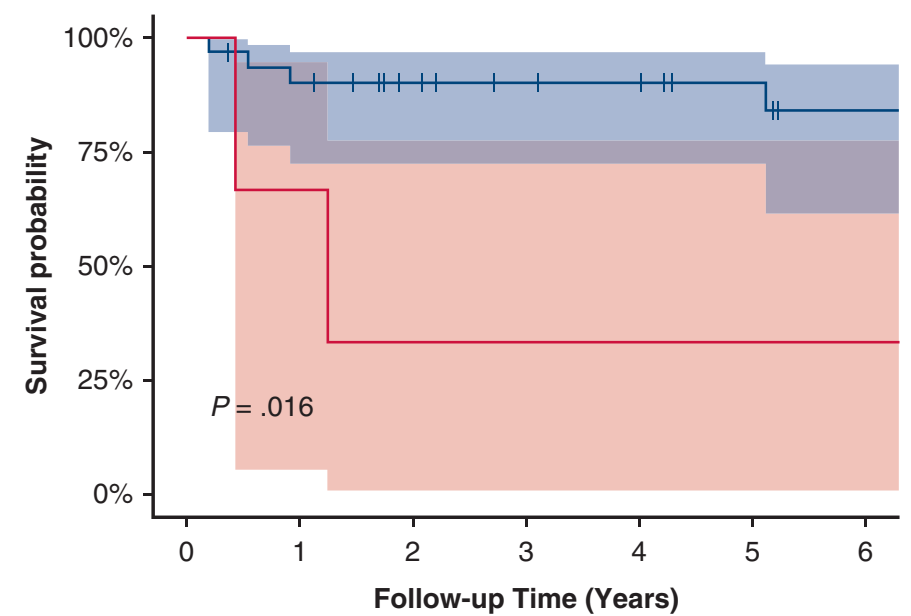

Number at risk

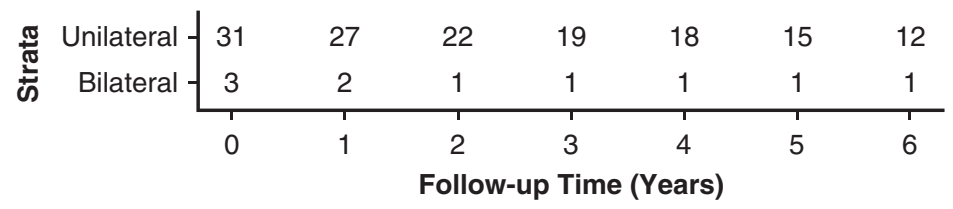

A

Strata + Unilateral + Bilateral

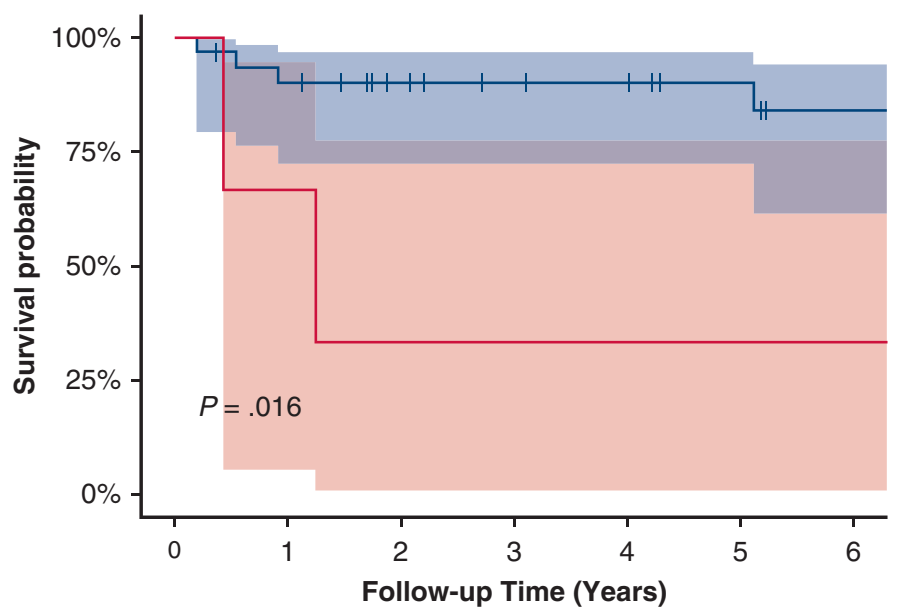

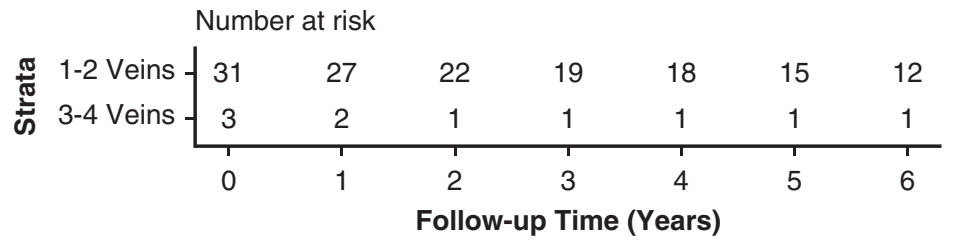

B

Strata + 1-2 Venis + 3-4 Venis

FIGURE 3. Kaplan-Meier survival (including $95 \%$ confidence intervals) following surgical repair of primary pulmonary vein stenosis. A, stratified by unilateral (blue) pulmonary vein involvement versus bilateral ( $\mathrm{red}$ ) pulmonary vein involvement. Bilateral pulmonary vein involvement is associated with inferior survival. B, Number of involved pulmonary veins (1 or 2 [blue] vs 3 or 4 [red]). Increased number of involved pulmonary veins is associated with inferior survival. 
patients and consequently prematurity was not identified as a significant factor for mortality. For example, if we examine the entire population of PPVS patients who have undergone PPVS intervention at our institution $(n=46$, including 12 initial percutaneous intervention patients), the incidence of prematurity is increased to $35 \%$ and for that entire cohort, we identified that prematurity was associated with poor survival. This is likely related to associated comorbidities and potentially a more extensive disease.

For our surgical cohort, we identified that increased extent of the disease, evidenced by bilateral disease, larger number of pulmonary veins involved, and higher PPVS severity score were associated with mortality and reintervention risks. This is comparable to other recent single and multi-institutional reports that demonstrated that bilateral disease was significantly associated with recurrence and mortality. ${ }^{2-5}$ Short of utilizing PPVS severity score, we have not examined the association of upstream stenosis in the intraparenchymal veins with recurrence and consequent mortality following surgical repair; but this is likely a very important factor determining early and late outcomes. Several groups have generated scoring systems for severity of PPVS, and in retrospective studies they have shown correlation between severity score and outcomes, both mortality and reintervention. ${ }^{2,3,12}$ Comparison between various studies is limited by the lack of uniform definition of the extent of pulmonary vein stenosis disease and the lack of an accepted universal PPVS severity score. This problem is compounded by the small number of patients who can be collected from 1 center and consequently the inability of any single institution series to provide adequate analysis that could provide diagnostic, grading, and management guidelines.

The sutureless technique has now been commonplace for almost 2 decades and has been shown to decrease pulmonary vein stenosis in patients undergoing primary surgical repair of TAPVC or pulmonary vein stenosis subsequent to TAPVC surgery. ${ }^{1,3,7,10,11,13-15,19-21,35}$ This sutureless technique has been our procedure of choice for patients with PPVS. Nonetheless, in our current series, sutureless technique was not associated with improved outcomes and that is likely due to the heterogeneous nature of this disease and the small number of patients who underwent other surgical procedures at our institution. Other reports have also failed to demonstrate a benefit of the sutureless technique in PPVS. Although that is likely again related to statistical limitations, it is also possible that this is related to different recurrence mode with the majority of PPVS patients having recurrence due to progressive upstream disease rather than local stricture at the repair site that is usually lessened with the sutureless technique. ${ }^{1-4}$ Nonetheless, the sutureless technique continues to be the preferred technique in this patient population, mainly for the perceived advantages and the documented benefit in secondary pulmonary vein stenosis repair.

Given the disappointing results with surgical repair of PPVS, alternative treatment modalities have been explored, including percutaneous interventions. Several groups have reported outcomes of percutaneous interventions for pulmonary vein stenosis in children utilizing various techniques, including balloon angioplasty, cutting balloons, cryotherapy, and stent placement. Unfortunately, the results have also been imperfect with a discouraging high incidence of recurrence of stenosis. ${ }^{23-26}$ The aim of the current series is to describe surgical outcomes and not to report on contemporaneous children who have received percutaneous intervention for PPVS, especially given our institutional bias with premature infants and those with more diffuse disease more likely to receive initial percutaneous intervention. Our percutaneous outcomes have been poor and even inferior to those following surgical repair and that is likely due both to selection bias and to the inherent limitations of the technique with inevitable recurrent in-stent stenosis in a majority of patients. Additionally, several groups have investigated the role of adjuvant medical therapy in decreasing the recurrent stenosis risk following surgical or percutaneous intervention. ${ }^{27-29}$ A piglet study of pulmonary vein stenosis used losartan administration as medical therapy to block transforming growth factor beta and showed some benefit to prophylactic therapy following surgical repair of pulmonary vein stenosis. ${ }^{27}$ Additionally, a recent study of vinblastine and methotrexate (targeted therapy for cell proliferation) in children with pulmonary vein stenosis resulted in unfavorable toxicity profiles with limited effect on disease outcomes. ${ }^{29}$ Clearly, more research is necessary to identify medical targets to treat and prevent recurrent stenosis in this challenging disease.

\section{CONCLUSIONS}

Despite being the largest series examining treatment outcomes of PPVS, our study is limited statistically by small sample size and the heterogeneity of this disease. The knowledge gap is especially high with regard to the pathophysiology of the disease, optimal diagnostic or treatment modality, and the role of adjuvant medical therapy. Given the rarity of this disease, variations in the treatment approaches among cardiac centers and likely within the same center, and the lack or effective protocols for the detection, management, and follow-up of those challenging patients multi-institutional studies seem to be necessary to bridge this knowledge gap, explore innovative treatment options, and create applicable management protocols that could improve the outlook for children with PPVS. A group from the University of Toronto has developed the Pulmonary Vein Stenosis Network (www.pvsnetwork.org) to 
coordinate enhanced collaboration between multiple institutions to create a registry that would help to achieve the above-mentioned goals. Those efforts will likely provide the best hope for a dramatic improvement in long-term survival and durability of repair of this challenging disease.

\section{Conflict of Interest Statement}

Authors have nothing to disclose with regard to commercial support.

\section{References}

1. Viola N, Alghamdi AA, Perrin DG, Wilson GJ, Coles JG, Caldarone CA. Primary pulmonary vein stenosis: the impact of sutureless repair on survival. J Thorac Cardiovasc Surg. 2011;142:344-50.

2. Shi G, Zhu Z, Chen H, Zhang H, Zheng J, Liu J. Surgical repair for primary pulmonary vein stenosis: single-institution, midterm follow-up. J Thorac Cardiovasc Surg. 2015;150:181-8.

3. Kalfa D, Belli E, Bacha E, Lambert V, di Carlo D, Kostolny M, et al. Primary pulmonary vein stenosis: outcomes, risk factors, and severity score in a multicentric study. Ann Thorac Surg. 2017;104:182-9.

4. Seale AN, Webber SA, Uemura H, Partridge J, Roughton M, Ho SY, et al. Pulmonary vein stenosis: the UK, Ireland and Sweden collaborative study. Heart. 2009;95:1944-9.

5. Charlagorla P, Becerra D, Patel PM, Hoyer M, Darragh RK. Congenital pulmonary vein stenosis: encouraging mid-term outcome. Pediatr Cardiol. 2016;37:125-30.

6. Holt DB, Moller JH, Larson S, Johnson MC. Primary pulmonary vein stenosis. Am J Cardiol. 2007;99:568-72.

7. Devaney EJ, Ohye RG, Bove EL. Pulmonary vein stenosis following repair of total anomalous pulmonary venous connection. Semin Thorac Cardiovasc Surg Pediatr Card Surg Annu. 2006;51-5.

8. Lo Rito M, Gazzaz T, Wilder T, Saedi A, Chetan D, Van Arsdell GS, et al. Repair type influences mode of pulmonary vein stenosis in total anomalous pulmonary venous Drainage. Ann Thorac Surg. 2015;100:654-62.

9. Quinonez LG, Gauvreau K, Borisuk M, Ireland C, Marshall AM, Mayer JE, et al. Outcomes of surgery for young children with multivessel pulmonary vein stenosis. J Thorac Cardiovasc Surg. 2015;150:911-7.

10. Kanter KR, Kirshbom PM, Kogon BE. Surgical repair of pulmonary venous stenosis: a word of caution. Ann Thorac Surg. 2014;98:1687-91.

11. Lacour-Gayet F. Surgery for pulmonary venous obstruction after repair of total anomalous pulmonary venous return. Semin Thorac Cardiovasc Surg Pediatr Card Surg Annu. 2006;45-50.

12. Lo Rito M, Gazzaz T, Wilder TJ, Vanderlaan RD, Van Arsdell GS, Honjo O, et al. Pulmonary vein stenosis: severity and location predict survival after surgical repair. J Thorac Cardiovasc Surg. 2016;151:657-66.

13. Devaney EJ, Chang AC, Ohye RG, Bove EL. Management of congenital and acquired pulmonary vein stenosis. Ann Thorac Surg. 2006;81:992-5.

14. Yun TJ, Coles JG, Konstantinov IE, Al-Radi OO, Wald RM, Guerra V, et al. Conventional and sutureless techniques for management of the pulmonary veins: evolution of indications from postrepair pulmonary vein stenosis to primary pulmonary vein anomalies. J Thorac Cardiovasc Surg. 2005;129:167-74.

15. Lacour-Gayet F, Zoghbi J, Serraf AE, Belli E, Piot D, Rey C, et al. Surgical management of progressive pulmonary venous obstruction after repair of total anomalous pulmonary venous connection. J Thorac Cardiovasc Surg. 1999;117: 679-87.
16. Sadr IM, Tan PE, Kieran MW, Jenkins KJ. Mechanism of pulmonary vein stenosis in infants with normally connected veins. Am J Cardiol. 2000;86:577-9.

17. Kato H, Fu YY, Zhu J, Wang L, Aafaqi S, Rahkonen O, et al. Pulmonary vein stenosis and the pathophysiology of "upstream" pulmonary veins. J Thorac Cardiovasc Surg. 2014;148:245-53.

18. LaBourene JI, Coles JG, Johnson DJ, Mehra A, Keeley FW, Rabinovitch M. Alterations in elastin and collagen related to the mechanism of progressive pulmonary venous obstruction in a piglet model. A hemodynamic, ultrastructural, and biochemical study. Circ Res. 1990;66:438-56.

19. Lacour-Gayet F, Rey C, Planche C. Pulmonary vein stenosis. Description of a sutureless surgical procedure using the pericardium in situ. Arch Mal Coeur Vaiss. 1996;89:633-6.

20. Najm HK, Caldarone CA, Smallhorn J, Coles JG. A sutureless technique for the relief of pulmonary vein stenosis with the use of in situ pericardium. J Thorac Cardiovasc Surg. 1998;115:468-70.

21. Vanderlaan RD, Caldarone CA. The ongoing evolution of sutureless repairs for pulmonary veinanomalies. Semin Thorac Cardiovasc Surg. 2016;28: 485-6.

22. Ungerleider RM, Johnston TA, O'Laughlin MP, Jaggers JJ, Gaskin PR. Intraoperative stents to rehabilitate severely stenotic pulmonary vessels. Ann Thorac Surg. 2001;71:476-81.

23. McMahon CJ, Mullins CE, El Said HG. Intrastent sonotherapy in pulmonary vein restenosis: a new treatment for a recalcitrant problem. Heart. 2003;89:E6.

24. Seale AN, Daubeney PE, Magee AG, Rigby ML. Pulmonary vein stenosis: initial experience with cutting balloon angioplasty. Heart. 2006;92:815-20.

25. Balasubramanian S, Marshall AC, Gauvreau K, Peng LF, Nugent AW, Lock JE, et al. Outcomes after stent implantation for the treatment of congenital and postoperative pulmonary vein stenosis in children. Circ Cardiovasc Interv. 2012;5: 109-17.

26. Bingler MA, Darst JR, Fagan TE. Cryo-balloon angioplasty for pulmonary vein stenosis in pediatric patients. Pediatr Cardiol. 2012;33:109-14.

27. Zhu J, Ide H, Fu YY, Zhao L, Coles JG, Caldarone CA, et al. Losartan ameliorates "upstream" pulmonary vein vasculopathy in a piglet model of pulmonary vein stenosis. J Thorac Cardiovasc Surg. 2014;148:2550-7.

28. Chai PJ. Losartan for progressive pulmonary vein stenosis: a possible solution? J Thorac Cardiovasc Surg. 2014;148:2559.

29. Rehman M, Jenkins KJ, Juraszek AL, Connor JA, Gauvreau K, Muneeb MS, et al. A prospective phase II trial of vinblastine and methotrexate in multivessel intraluminal pulmonary vein stenosis in infants and children. Congenit Heart Dis. 2011;6:608-23.

30. Fine JP, Gray RJ. A proportional hazards model for the subdistribution of a competing risk. J Am Stat Assoc. 1999;94:496-509.

31. Drossner DM, Kim DW, Maher KO, Mahle WT. Pulmonary vein stenosis: prematurity and associated conditions. Pediatrics. 2008;122:e656-61.

32. Gowda S, Bhat D, Feng Z, Chang CH, Ross RD. Pulmonary vein stenosis with Down syndrome: a rare and frequently fatal cause of pulmonary hypertension in infants and children. Congenit Heart Dis. 2014;9:E90-7.

33. Eyries M, Montani D, Girerd B, Perret C, Leroy A, Lonjou C, et al. EIF2AK4 mutations cause pulmonary veno-occlusive disease, a recessive form of pulmonary hypertension. Nat Genet. 2014;46:65-9.

34. Eghtesady P. Primary pulmonary vein stenosis: can we expect different results? J Thorac Cardiovasc Surg. 2015;150:188-9.

35. Honjo O, Atlin CR, Hamilton BC, Al-Radi O, Viola N, Coles JG, et al. Primary sutureless repair for infants with mixed total anomalous pulmonary venous drainage. Ann Thorac Surg. 2010;90:862-8.

Key Words: pulmonary vein stenosis 


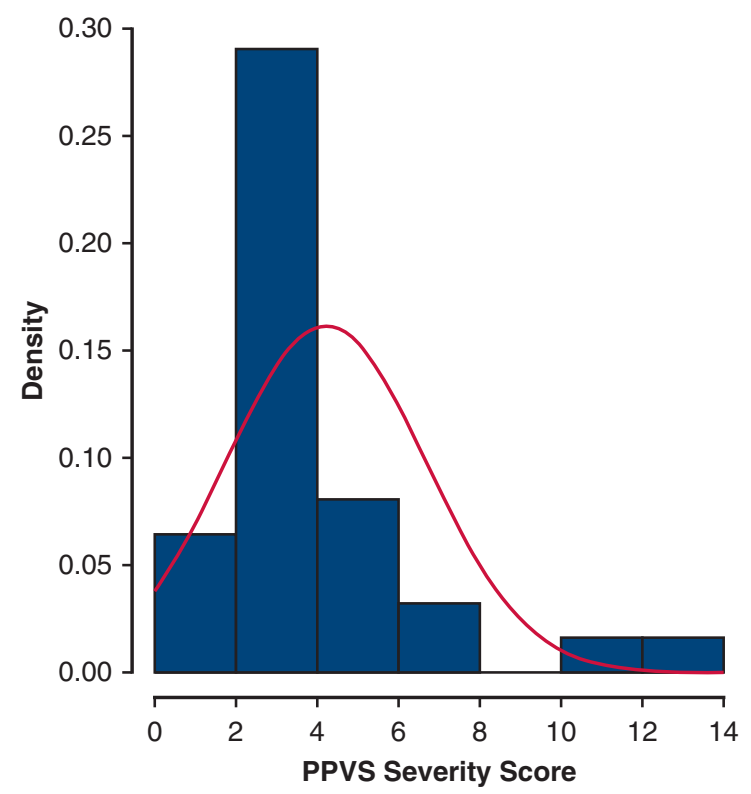

FIGURE E1. Histogram and density curve showing distributional shape and spread of primary pulmonary vein stenosis $(P P V S)$ severity scores.

TABLE E1. Characteristics of patients with primary pulmonary vein stenosis (PPVS) who underwent surgical versus percutaneous intervention

\begin{tabular}{|c|c|c|c|c|c|c|c|}
\hline Characteristic & $\mathbf{N}$ & $\begin{array}{l}\text { All patients } \\
(\mathrm{N}=46\end{array}$ & $\mathbf{N}$ & $\begin{array}{l}\text { Percutaneous patients } \\
\qquad(\mathrm{n}=12\end{array}$ & $\mathbf{N}$ & $\begin{array}{l}\text { Surgical patients } \\
\quad(\mathbf{n}=\mathbf{3 4})\end{array}$ & $P$ value \\
\hline Male gender & 46 & $20(43.5)$ & 12 & $6(50.0)$ & 34 & $14(41.2)$ & .596 \\
\hline Prematurity* & 46 & $16(34.8)$ & 12 & $10(83.3)$ & 34 & $6(17.7)$ & $<.001$ \\
\hline Genetic syndrome & 46 & $13(28.3)$ & 12 & $4(33.3)$ & 34 & $9(26.5)$ & .717 \\
\hline Age at intervention (mo) & 46 & $7.8(5.3-16.1)$ & 12 & $5.9(4.6-9.7)$ & 34 & $8.9(5.9-18.4)$ & .219 \\
\hline $\begin{array}{l}\text { Pulmonary vein involvement } \\
\text { Bilateral } \\
\text { Unilateral }\end{array}$ & 46 & $\begin{array}{c}4(8.7) \\
42(91.3)\end{array}$ & 12 & $\begin{array}{c}1(8.3) \\
11(91.7)\end{array}$ & 34 & $\begin{array}{c}3(8.8) \\
31(91.2)\end{array}$ & 1.000 \\
\hline $\begin{array}{l}\text { No. of veins involved } \\
\quad \begin{array}{l}1 \text { or } 2 \\
3 \text { or } 4\end{array}\end{array}$ & 46 & $\begin{array}{c}43(93.5) \\
3(6.5)\end{array}$ & 12 & $\begin{array}{c}12(100) \\
0(0)\end{array}$ & 34 & $\begin{array}{c}31(91.2) \\
3(8.8)\end{array}$ & .557 \\
\hline $\begin{array}{l}\text { Maximum preoperative gradient }(\mathrm{mm} \mathrm{Hg}) \\
\quad \leq 12 \dagger \\
>12\end{array}$ & 40 & $\begin{array}{l}27(67.5) \\
13(32.5)\end{array}$ & 11 & $\begin{array}{l}7(63.6) \\
4(36.4)\end{array}$ & 29 & $\begin{array}{r}20(69) \\
9(31)\end{array}$ & 1.000 \\
\hline
\end{tabular}

Values are presented as $\mathrm{n}(\%)$ or median (interquartile range). "Defined as $\leq 36$ weeks. †Patients with pulmonary vein atresia were included in this group. 